\title{
The Mediterranean Variety of Capitalism, Flexibility of Work Schedules, and Labour Productivity in Southern Europe
}

\author{
Alberto Vallejo-Peña ${ }^{1}$, Sandro Giachi ${ }^{2}$ \\ ${ }^{1}$ Universidad de Málaga, Málaga, Spain \\ ${ }^{2}$ University of Sussex, Brighton, United Kingdom \\ Received: 13 September 2017/Accepted: 23 August 2018
}

\begin{abstract}
Sociology has long been used to highlight the existence of diverse institutional models between geographical areas of Europe in terms of work organization. Based on this, we propose to compare the situation of four representative countries of Southern Europe (Spain, Italy, Greece and Portugal) with that of the rest of Europe, by addressing the number of hours worked and the flexibility of working hours as key elements of their institutional model of work organization, as well as their impact on levels of labour productivity. Taking the model of the varieties of capitalism as a reference, this study compares the behaviour of the Mediterranean (Southern) countries with other European regions. Indicators have been obtained from the 2010 and 2015 iterations of the European Working Conditions Survey (EWCS) that include the number of hours worked, the flexibility in the hours of entry and exit, and the tendency to work the same number of hours per day. After comparing averages in both iterations and applying linear regressions, the following conclusions have been reached: (1) Productivity in Southern countries is on a par with the European average but far from the more corporatist and liberal (northern) areas; (2) the South maintains a high average of hours worked (above the European average) to compensate for the poor productivity of its hours; and (3) the incorporation of flexible schedules is associated with elevated levels of productivity.
\end{abstract}

JEL classification: J81, P52, B52

Key words: Economies of Southern Europe, European crisis, PIGS, Varieties of capitalism

\section{Introduction}

The development of the political, economic, and social project of the European Union (EU) recently highlighted the historical heterogeneity of Europe. Indeed, from an external point of view, Europe may be something more than a continent: it is a geographical area united by its history, the core territory for the development of the Western society that generated this political, cultural, and economic phenomenon called Eurocentrism (Brennetot et al. 2013). However, such a model gradually declined in front of emergent regions such as the United States (U.S.) since the beginning of the 20th century, and 
South-Eastern Asia during the last three decades (Lamo de Espinosa 2010). To what degree has the heterogeneity of Europe contributed to its current situation? Despite the difficulty in responding to such a question, our work looks at some key elements of national organizational cultures. Among the evident economic and cultural differences existing within Europe, we highlight those that - in our opinion - have led to the Southern European countries ('the South') being labelled as a threat to the stability of the European Union. These refer to a specific historical cycle: countries like Spain and Portugal maintained their historical weight during their colonial period, after completing their 'brilliant' cycle during the age of discoveries and mercantilism. Likewise, Italy was a very relevant node for the international economy and commerce between the 14th and the 16 th centuries. Afterwards, the Industrial Revolution was a key stage that turned the situation around and favoured Northern countries.

More recently, Spain, Italy, Greece, and Portugal joined the European Union in evident conditions of backwardness when compared with their Northern partners. Nevertheless, the growth of the Italian economy during the 1980s led to its Gross Domestic Product (GDP) per capita being on a par with that of the United Kingdom (U.K.) at various times during that decade. Furthermore, the significant economic growth of Spain between the 1990s and the beginning of the 21st century, suggested that the "European dream" of equilibrating the North-South balance was an achievable goal. By contrast, the fall of both countries (Italy and Spain) after the "Lehmann Brothers" crash in 2008 suggested that the period of prosperity of previous years was based on a temporary favourable situation, betraying - in turn - their shortcomings in terms of innovation, technology, industrialization, and creation of employment. Likewise, Portugal and Greece recently experienced a gradual deterioration in their economies. The Greek situation was particularly critical, due to the country's indebtedness and the consequent threat to the eurozone. $^{1}$

Regarding the labour performance of Southern European countries, evidence corroborates some weaknesses when compared with the North. Portugal and Greece show concerning outcomes in terms of productivity per worked hour: 100 being the average of EU-28, they score 70.1 and 70.6 respectively, while Italy (101.7) and Spain (101.1) are closer to the average. But all these countries are far from the scores of their Northern partners such as Belgium (134.7), the Netherlands (129.5), France (128.0) and Germany (127.0). A report by the McKinsey Global Institute (MGI 2010), assigning 100 points to the current level of labour productivity of the U.S., gives 84 points to Northern Europe, and 73 points to Southern European countries. The report concludes as follows: while the productivity of Europe was closer to the U.S. during the $90 \mathrm{~s}$, since the beginning of the new century it continues to decrease, burdened by Southern countries that have embarked on a 'non-sustainable' path.

In addition, the elevated public deficit of the South has led to a conflict with their European partners that are not impressed with the South's governance and economic performance. The most significant criticisms include the following examples: the trend toward the waste of public money, "clientelism", management inefficiencies, overweight of the public administration sector, and - above all - the poor levels of labour productivity. A prominent Spanish sociologist, Lamo de Espinosa (2010, p. 543) affirmed that: "This situation provoked serious concerns about the solidity and the potential of the Spanish economy and, to a lesser extent, about the reaction capacity of both its institutions and political elite. International press condemned Spain to the fellowship of the PIGS (Portugal, Italy, Greece, Spain): a stigma that will last for a long time." (Translation provided by the authors)

Scholars have often recognized that these inequalities rely on the existence of a gap in

\footnotetext{
${ }^{1}$ Given the difficulties of financing manifested by Southern European countries and their incapability of generating sustainable economic growth, some Northern partners and institutions reported such situation as a waste of their financial contributions to the Union. Did the South create a 'subvention culture'? Public aid to peripheral and convergence regions - justified by rebalancing goals - ended with a positive, but temporary and fictitious effect that dwindled out as aid reduced over time (De la Fuente 2005). More pessimistic scholars have suggested that aid from the European Union to underdeveloped regions had almost no effect on rebalancing structural gaps between Northern and Southern countries in terms of employment, innovation, industry fabric, and technology (González Rodríguez et al. 2000).
} 
terms of production and the occupational model. For instance, Miguélez, Prieto (2009) focused on the construction of an unbalanced labour model diminishing the value of the working class. While Northern Europe consolidated a stable model for employment during the 1950-80 period, "Southern European countries were left behind because of the concentration of low-quality employment and the low levels of inclusion of women in the labour market". Miguélez, Prieto (2009, p. 276; translation provided by the authors) In addition, since the $80 \mathrm{~s}$, this framework was subsequently weakened by new factors that jeopardize social rights: "First of all, the strength of the system of labour relations of each country; and then, the inclusion within the employment system of new labour actors that are different from the adult white male, such as the youth, women, and immigrants. [... In countries like Spain the dualism of the labour model is clearly evident." (Miguélez, Prieto 2009, p. 276; translation provided by the authors)

Regarding the recent application of governmental policies that promote productivity in Southern Europe, we observed two main lines of action: policies to reduce working time and those aimed at flexicurity. Regarding the first case, the promotion of low-wage policies in the European Union since the early 2000s stands out. Its applications, both in the North and in the South, do not work properly, at least from a productivity perspective (Perrons 2005). The model of contracting workers for short periods with low wages is compensated with the incentive of occupying the rest of the day with other dedications and even a second job, in addition to having tax benefits and exemption from Social Security. However, the subsequent results - both in the north and in the south - showed some reinforcement of situations of poverty, lack of worker motivation and feminization of these contracts, which reinforced the figure of the male breadwinner. Among the forms adopted in Europe, the consolidation of the German mini-job model stands out, by finding the right context for its development, as Feld et al. (2015) indicated in a recent work. According to them, "many of those with a mini-job are second earners, students and pensioners [...] and compared to other European countries, Germany's support system is rather generous" (Feld et al. 2015, p. 3). Given those circumstances, to export such a model successfully to Southern countries shows several difficulties. In terms of policies aimed at flexicurity, expectations are somewhat more optimistic. In a study conducted by a mixed team of Spanish and Italian researchers, they focused on the following question: is flexicurity exportable (Leonardi et al. 2011)? Although Italy and Spain are labour markets that are traditionally rigid and conditioned by cultural factors, some steps have been taken in this direction through dialogue between social actors, and there is considerable room for improvement if the work training is adapted to the new times and the mediation between supply and demand.

With these relevant policy issues in mind, we expose in this paper the outcomes of our research into the differences of labour productivity and national models of work organization between culturally and historically similar Southern European countries (Italy, Spain, Portugal, and Greece) and the rest of the EU, giving special attention to Northern countries. We used data from the fifth (2010) and sixth (2015) iterations of the European Working Conditions Survey (EWCS) performed by the European Foundation for the Improvement of Living and Working Conditions (EUROFOUND), located in Dublin, Ireland. We identified a number of measures relating to the flexibility of working schedules as indicators of national organizational models. The second section details the theoretical framework; the third section describes research goals, design, and methodology; the fourth section shows the findings, while the last section details the conclusion of this study.

\section{Varieties of capitalism, work organization, and time management}

The starting point of our research is the assumption that the national context affects economic factors like organizational and work practices. The influence of the work of Inglehart (1997), who oriented his studies toward the value of interculturalism and toward cross-country differences, was crucial for studying national cultures. Likewise, we should highlight the research performed by Esping-Andersen (1999), connecting national cultures with the socio-political context. This scholar identified three models of development of the 
welfare state across western countries since the end of World War II: liberal, conservative, and social democratic. Beyond the public sector, every (public or private) organization is embedded within such models.

Likewise, we should take into account the contributions from the neo-institutionalist research approach. Mauro Guillén (1994), the author of 'Models of Management', tackles such differences according to the economic and labour relations existing internally in each country. The thesis that the traditions of different countries mark their institutional relations and shared ideology is useful in explaining most of the existing organizational and labour conflicts, thereby generating a diversified set of paradigms. For example, it is part of the stream that underlies contrasting conceptual axes such as 'Catholic versus Protestant' or 'liberal versus conservative'. In each country, we find institutional struggles that determine the dominance of a certain paradigm. This approach helps us to understand the different organizational models existing across countries and nations. Specifically, we state that a neo-institutional approach is useful for addressing the socio-political diversity of European countries and its impact on labour productivity. Some empirical studies have included a similar approach, like the global comparative exercise performed by Hall, Jones (1996); the comparative studies about Canadian regions performed by Baldwin et al. (2005) and Maynard (2007) and the analysis of the Spanish economy coordinated by Segura (2006). Such approximations show that institutional relations encompass one of the most relevant components of a national economy in facilitating labour productivity, technological capacity, workforce qualification and internationalization. Therefore, we find several studies connecting labour productivity with the existence of values, norms, and rules (the institutional framework) facilitating the flexibility of the labour system and the cultural value of work organization.

Within the neo-institutional literature, a relevant contribution is provided by the 'varieties of capitalism' literature (Hall, Soskice 2001). These studies highlighted the relevance of national institutions within the economic structure, using conditioning variables such as innovation and performance. The varieties of capitalist models across countries and territories have historical reasons and imply different values and beliefs. The institutional effect primarily manifests itself in the governance mechanisms of industrial relations. These factors condition the capacity of nations (and their firms) to adapt to the challenges posed by globalization and the emergence of the knowledge economy (Castells 1997, Hall, Soskice 2001). Organizational flexibility of markets and firms (e.g. through new models of labour relations or network organizations) stands out as a key factor to foster firms' productivity and competitiveness.

This approach recognizes the existence of different ideal types of organization for the capitalist economy in Europe (Crouch 1998). For instance, some studies highlight the existence of a 'Mediterranean' model of capitalism for countries such as Italy, Spain, Portugal, and Greece (Amable 2003). The idea of a Mediterranean model of capitalism takes its origin from the existence of a large set of family-based small firms, crossparticipation in firms' governance and the prominent role of the State in the economy (Moerland 1995, Regini 1995), a system that De Jong (1995, p. 402) defined as a 'pragmatic' one. According to Amable (2003), this variety of capitalism is significantly different to the liberal (or Anglo-Saxon) model that is based on the balance between the limiting and creative effect of institutions on the economy through formal regulation mechanisms. Moreover, some countries of central Europe (e.g. Germany) adopt a 'corporatist' market economy, while Scandinavian countries adopt a social-democratic model (Amable 2003). These models, especially the latter, stand out for their level of long-range planning on national public policies while, at the same time, firms' recruitment strategies do not necessarily rely on close social networks. As Cassano (1996) points out, there are historical and cultural reasons explaining why Mediterranean countries developed a peculiar way of understanding organization, work, and time.

Specifically, the Mediterranean model of capitalism "is similar to the Continental European model, but based on more employment protection and less social protection. Employment protection is made possible by a relatively low level of product-market competition and the absence of short-term profit constraints as a consequence of the centralization of the financial system. However, a workforce with limited skills and 
education level does not allow for the implementation of high wages and high skills industrial strategy" (Amable 2009, p. 21), while "Mediterranean countries appear to possess more regulated labour markets than other European economies" (Amable 2003, p. 17). Therefore, the Mediterranean model is more rigid than others are in terms of governance and organization of employment. Formal employment protection prevents quick structural change, while low competitive pressure simultaneously allows employment stability in large firms. This situation also hinders the need for upgrading the competences of the workforce and, therefore, potential pathways for innovation and productivity (Amable 2003, p. 113). ${ }^{2}$

In conclusion, (Amable 2003, 2009) suggested that the rigidity of the labour market in Southern European countries seriously hinders the capacity of their firms to compete and, therefore, he recommended exploring more 'flexible' forms of governance and organization of work. However, as Meardi (2012, p. 58-59) pointed out, this supposed 'rigidity' of Mediterranean countries should be considered according to some dimensions and not others: for instance, Spain (and Portugal) showed very high levels of temporary work for a very long period, in contrast with the situation of Italy and Greece. This difference originated in the different degrees of conflict in industrial relations and strength of unionism. By contrast, rigidity looks to be a common feature of all Mediterranean countries as it comes to the daily organization of work, as it can be exemplified by the rigidity of the working-time schedules.

Drawing from the considerations above mentioned, our research hypothesis is the following: the Mediterranean model of capitalism is less productive because of the low flexibility of the organization of working time and schedules, among other factors. Alongside the theoretical contributions exposed above, there is evidence of significant differences in work schedules between Northern and Southern European countries. For instance, it is well-known that workdays in the north used to end relatively early (usually around 18:00 hours) versus the extensive working evening typical of Mediterranean private firms. In this sense, the work gets more centrality in Southern countries' work schedules. Among the explanations for the overloading of working time we highlight the studies of Paugam (2007) and Halbwachs (2002). They recognize the difficulty of Southern societies in separating working time from private or social time. They also found a historical trend within Southern countries to split the workday in two. This probably derives from diverse factors like climate or the 'moonlighting' tradition that evolved as a consequence of recurrent famines (i.e. an additional evening job to compensate for the difficulties in obtaining income). The 'classic' works of the German sociologist Georg Simmel (1998) went further in its implications by placing Southern Europe as an example of 'integrated poverty': a situation addressing a large part of the population, contagious and reproductive in nature, and weakened by a strong component of "clientelism" and informal economy. Simmel identified family solidarity as the solution adopted by the lower classes for addressing this problem in Mediterranean countries. Familism and 'clan culture' (Banfield 1958, Pizzorno 1966, López-Pintor, Wert 1982) contribute to impeding the separation between work and private space and time. In conclusion, this complex convergence of diverse factors provoked a specific model of adaptation that is no longer relevant to current societies and economies, thereby causing a societal disorder of work organization.

This tendency towards work time overloading worsened after the Great Recession of 2008 with its consequent social cuts to public expenditure in Greece, Spain, and Portugal, causing a fall of salaries and an unbalanced context for negotiation between workers and private firms. Additional problems came from the increase of mandatory working hours in the public sector in these countries that, likewise, reduced the number of temporary workers employed by the public administration.

On the other hand, the low productivity of the countries of the south is also explicable by political science, focusing on the forms of government. In this sense, Migdal (1998) developed his perspective "State in society" that conceives the State as an area of

\footnotetext{
${ }^{2}$ Another key feature of the Mediterranean model is specialization in light industries and low-tech activities, as well as heavy product-market regulation, hindering technological innovation and entrepreneurship - as confirmed by the lagging position that Southern European countries have in terms of ICTs (Amable 2003, ch. 1).
} 
power marked by the use of force, and where the legal and institutional framework is complemented by informal processes and power relations. The State is not only influenced by international and global issues, but also - to a large extent - by social and ideological interests of a local or regional nature. In this same line, the perspective of "neopatrimonialism" helps to explain the dysfunctions of many governments of the planet. The classic work of Bratton, Van de Walle (1997), Democratic experiences in Africa (see also Van de Walle 2005), speaks of a strong transmission of the interests of certain social groups toward government mechanisms that prevented genuine development of democracy. The authors identify as characteristics of a "neopatrimonialist" government: (1) "presidentialism", understood as the concentration of power in a few hands; (2) "clientelism"; and (3) The use of state resources for private interests. Approaching the case of Latin American governments, Bechle (2010) explains that society has not found a way to control political power, since it operates continuously crossing the border between public and private. Weber, according to Bechle, predicted that a patrimonial stage in the governments would give way to the domain of the legal system, but this phase has been completed by a select group of countries (Northern Europe being a reference). In the Latin American case, however, there is a particular context in which private interests and patrimonial forms continue to be active, under the cover of legality. Maya (2016) has reinforced these arguments in her recent work on the decline of "Chavism" in Venezuela. In this sense, the southern European countries correspond to the model only partially, but the theory warns of the existence of strong patronage networks in the environment of their governments (Villena 2017).

Among the most relevant strategies promoted by the policy and management sector to foster labour productivity through a change in the working-time system are those strategies based on time flexibilization. There are two types of initiatives: on the one hand, the so-called passive flexibility (1) that enables the firm to adapt work schedules to workers' demands and needs by offering benefits like free days or salary incentives (Lusa, et 2007); or on the other hand, flexibility policies oriented to the personnel (2) fostering its satisfaction and motivation through improvement in work-family conciliation (Jijena-Michel, Jijena-Michel 2015, Lewis 2003). In both cases, and especially (2), the support perceived by the worker may be translated into positive attitudes with significant impacts on productivity, according to both Perceived Organizational Support Theory and Social Exchange theories (Lambert 2000). In this sense, earlier policies of flexibilization oriented toward the 'when' of the problem, were integrated with others oriented toward the 'where' and the 'to what extent' (Hill et al. 2008). In fact, recent empirical studies show that modifying the working schedule system of firms could improve both family-work conciliation and labour productivity (Basque Governement 2010).

\section{Methodology}

The aim of this research is to measure the flexibility of work schedules and its impact on labour productivity across Southern European countries by performing a comparison with three other areas previously defined by theory (varieties of capitalism approach). To achieve this aim, we designed a comparative and exploratory study. Our research used data from all EU-28 countries for theoretical and operational reasons (we use the average of European countries as a reference) even if our research design is focused on comparing the performance of the following four blocs of countries: ${ }^{3}$

\footnotetext{
${ }^{3}$ We excluded from this classification smaller countries (like Cyprus, Luxembourg, or Malta) because their institutional model is not clearly positioned according to the literature. For instance, it is not clear if Cyprus should be considered as a case of the liberal variety of capitalism, or mixed/Mediterranean. Likewise, the disproportionate levels of labour productivity exhibited by Luxembourg, probably due to its peculiar economic structure (e.g. international finance), prompted the exclusion of this country from the classification. Furthermore, almost all of the countries corresponding to the central or eastern part of Europe (following the United Nations's scheme) were not included in any bloc as most of them would correspond to the post-communist variety of capitalism. In this residual bloc, we also included the three Baltic countries (Estonia, Latvia, Lithuania) because these countries, despite the fact that they are part of the natural geographic region of North Europe (Figure 1), are - in our opinion - closer to the post-communist bloc, due to their history, culture, and economy, as also corroborated by their medium-low average levels of labour productivity (see Table 1).
} 


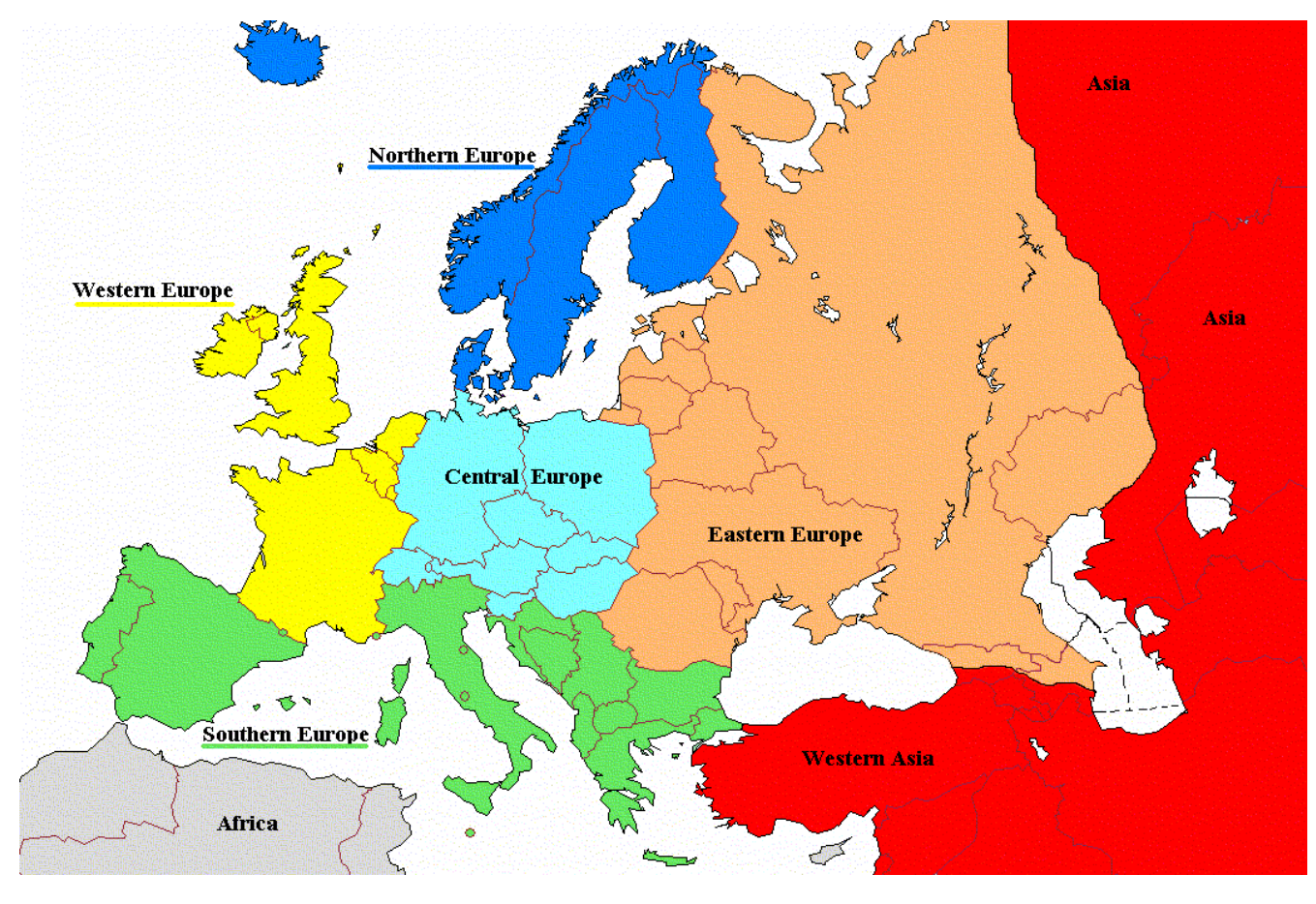

Source: United Nations Organization (UNO)

Figure 1: Classification of European countries by natural regions

1. The four big countries of Southern Europe being representative of the mixed (Mediterranean) model of capitalism: Italy, Spain, Portugal, and Greece. These countries encompass our main research object and show moderate levels of labour productivity.

2. The three countries of Western Europe following a liberal (Anglo-Saxon) model of capitalism: Ireland, the Netherlands, the U.K. These countries show a level of labour productivity higher than the average.

3. The three countries of Northern Europe following a social democratic (Scandinavian) model of capitalism: Denmark, Finland, and Sweden. These countries show a level of labour productivity higher than the average as well.

4. The four countries of western-central Europe following a corporatist (continental) model of capitalism: Austria, Belgium, France, and Germany. These countries show higher levels of labour productivity.

For building these blocs we took into account the diverse geographical areas of Europe according to the natural regions classification by the United Nations Organization (UNO; Figure 1), together with the scheme provided by the varieties of capitalism literature, according to Hall, Soskice (2001) and the extension realized by Amable (2003). ${ }^{4}$

We searched the content of available international surveys on issues like work and social values in order to identify measures for comparing many national varieties of work organization that exist across countries. We selected relevant and updated indicators relating to the EU-28 countries. Finally, we decided to analyse a set of indicators from the 5th and 6th waves of the EWCS (EUROFOUND 2016) as independent variables. Specifically, for each country, we used the percentage of surveyed workers affirming that:

1. Work less than $30 / 34$ hours each week ('underloaded workers')

2. Work more than 40 hours each week ('overloaded workers')

\footnotetext{
${ }^{4}$ However, Amable (2003, p. 14) pointed out clearly that the geographical correspondence of some models of capitalism in Europe should not be taken too literally, but only for "the sake of simplicity".
} 
3. Have rigid schedules to enter/exit at work ('rigid entry/exit schedule')

4. Work approximately the same number of hours every day ('rigid workday schedule')

The first two indicators refer to the amount of time employed for working, identifying the size of two groups of workers: on the one hand, underloaded workers, working a small number of hours each week (less than 30 in the 2010 survey, and less than 34 in the 2015 survey); on the other hand, overloaded workers, working more than 40 hours each week. Similarly, these data are compared with the real number of hours worked per week as reported by Eurostat for the year 2015. The latter two variables refer to the flexibility of working time, reflecting the rigidity of the national organizational model.

In summary, we analyse the relation between each one of these independent variables with the aggregated productivity at national level for each hour worked (dependent variable) as reported by Eurostat in 2010 and 2014 (data for 2015 are not available at the time of writing this paper). For each pair of variables (one by each wave), we built a scatter plot and estimated the lineal or polynomic slope and the correspondent coefficient of determination. The statistical formula behind this method is the following:

$$
Y_{i t}=\beta_{1} X_{j i t}^{2}+\beta_{0} X_{j i t}+K
$$

Where:

$Y_{i t} \ldots$ Productivity per worked hour for the country $i$ of year $t$

$X_{j i t} \ldots$ Independent variable (' $j$ ' being the proportion of 'underloaded workers', 'overloaded workers', or 'workers with rigid entry/exit schedule' or 'rigid workday schedule' respectively) for the country $i$ of year $t$

$K \ldots$ constant (intercept) of the model

The model has been estimated following a regular least squares regression procedure, performed through the Excel software.

In this way, we try to highlight the diverse outcomes obtained by geographic area, relating indicators of the number of hours worked and the flexibility of work schedules with labour productivity performance.

\section{$4 \quad$ Findings}

In this section, we describe the main findings of the study. We first tackle the trends underlying the data on labour productivity per worked hour (the dependent variable). This is followed by the results of the analyses of how productivity is influenced by the selected independent variables.

\subsection{Productivity per Worked Hour Within EU-28}

Table 1 shows the data on the levels of labour productivity of the 28 countries of the EU. We selected this measure for productivity due to the relation between GDP and the total number of hours that have been worked within the country. In this case, values have been standardized according to the average for the EU-28, which is 100 for each year. Countries have been ranked from higher levels to lower levels of productivity, taking 2010 as the reference year.

Looking at Table 1, we observe a few significant variations in the levels of labour productivity of countries between 2010 and 2014. Following the classification of natural regions, countries showing a higher than average levels of productivity are part of the Western Area (Luxembourg, Belgium, The Netherlands, Ireland, France) with the exception of the U.K., followed by Northern countries (Denmark, Sweden, Finland) and two countries of central Europe (Germany, Austria). Southern European countries occupy positions ranging from the EU-28 average (Italy, Spain) to lower than average levels (Greece, Portugal), along with the U.K., the Mediterranean countries and islands (Cyprus, Malta) and some countries of central Europe (Slovenia, Slovakia, Czech Republic). Eastern countries occupy the lower positions of the EU-28 labour productivity ranking. 
Table 1: Comparing productivity between European countries

\begin{tabular}{|c|c|c|}
\hline Country & 2010 & 2014 \\
\hline LU - Luxembourg & 173.9 & 182.0 \\
\hline $\mathrm{BE}-$ Belgium & 138.4 & 134.7 \\
\hline NL - Netherlands & 132.2 & 129.5 \\
\hline IE - Ireland & 128.9 & 129.0 \\
\hline FR - France & 128.8 & 128.0 \\
\hline DK - Denmark & 129.9 & 127.1 \\
\hline DE - Germany & 126.1 & 127.0 \\
\hline SE - Sweden & 118.1 & 114.8 \\
\hline AT - Austria & 113.5 & 113.4 \\
\hline FI - Finland & 110.0 & 106.5 \\
\hline IT - Italy & 103.7 & 101.7 \\
\hline ES - Spain & 99.5 & 101.1 \\
\hline EU28 - European Union (28 countries) & 100.0 & 100.0 \\
\hline UK - United Kingdom & 104.8 & 99.7 \\
\hline CY - Cyprus & 86.8 & 81.9 \\
\hline SI - Slovenia & 77.6 & 79.3 \\
\hline SK - Slovakia & 74.8 & 76.8 \\
\hline MT - Malta & 75.9 & 71.4 \\
\hline CZ - Czech Republic & 69.1 & 70.7 \\
\hline GR - Greece & 75.2 & 70.6 \\
\hline PT - Portugal & 68.6 & 70.1 \\
\hline HU - Hungary & 67.3 & 65.6 \\
\hline LT - Lithuania & 58.7 & 64.8 \\
\hline EE - Estonia & 60.7 & 62.9 \\
\hline HR - Croatia & 56.4 & 60.5 \\
\hline PL - Poland & 55.9 & 58.6 \\
\hline LV - Latvia & 49.6 & 53.6 \\
\hline RO - Romania & 43.7 & 49.4 \\
\hline BG - Bulgaria & 41.7 & 42.5 \\
\hline
\end{tabular}

Source: EUROSTAT

By contrast, if we follow the classification of European countries according to the varieties of capitalism scheme, we observe that countries from two groups occupy the higher productivity positions: the corporatist bloc (Belgium, Germany, France, and Austria) and the liberal bloc, excepting the U.K. (The Netherlands and Ireland). These are closely followed by the social-democratic bloc of countries (Table 1). Next we find the bigger countries of the mixed bloc (Italy, Spain) along with some countries of the Anglo-Saxon area. Finally, we find the other two 'mixed' economies down the ranking, together with the post-communist economies.

In summary, differences in the level of labour productivity correspond to both geographical patterns and models of capitalism. Specifically, we may identify a strong cluster of countries in north-western Europe formed by a combination of countries following either a liberal or corporatist model, encompassing a kind of 'productive European heart'. While the Scandinavian countries show similar levels of productivity, the Mediterranean countries recorded lower levels of productivity.

\subsection{Labour Productivity and Number of Worked Hours}

The analysis of the national behaviour relating to labour productivity implies looking at the differences in terms of time dedicated to the workday. We show the existing relationship between the aggregate levels of productivity per worked hour of each country (the dependent variable) and the percentage of underloaded workers in 2010 (Figure 2) and 2015 (Figure 3). We observe that Southern European countries show a percentage of 


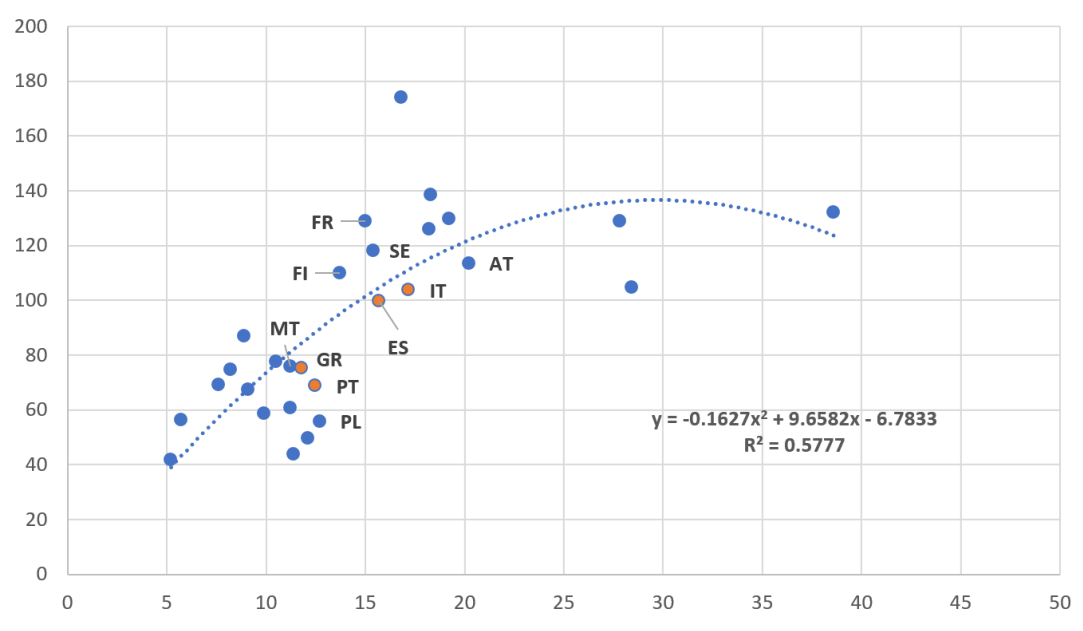

Source: EWCS

Figure 2: relation between productivity ( $y$-axis) and percent of underloaded workers $(x$-axis) 2010

underloaded workers close to the average: between $11 \%$ and $18 \%$ for 2010 , and between $18 \%$ and $27 \%$ for 2015 , excepting in the case of Italy for this year (something more than $30 \%$ of its workforce).

Both in 2010 (Figure 2) and 2015 (Figure 3), we observe that there is a significant correlation between labour productivity and the percentage of underloaded workers, as exemplified by the (adjusted) coefficient of determination, higher than 0.5 in both cases. The relation between both variables is illustrated by a positive 2 nd grade polynomic slope, growing faster in correspondence with lower levels of the independent variable (underloaded workers), and starting to decrease around a threshold of $30 \%$ for 2010 and $45 \%$ for 2015 (the difference is probably due to the diverse way of operationalizing the variable). This means that increasing the percentage of underloaded workers has a positive effect on productivity, at least until a certain threshold. In fact, all countries exceeding the European average (100) show a percentage of underloaded workers greater than the average (13\% for $2010,18 \%$ for 2015$)$.

Graphs 3 and 4 show the relation between the levels of aggregated productivity per worked hour and the percentages of overloaded workers for each country. Most of Southern European countries show relatively elevated levels for this indicator (between $21 \%$ and $25 \%$ ) while Greece leads the ranking both years with more than $43 \%$ of overloaded workers on its total workforce.

Both in 2010 and 2015 we observe a moderate correlation between productivity and overloaded workers, exemplified by the (adjusted) coefficient of determination, higher than 0.34 for 2010, and higher than 0.43 for 2015 . The relation between these two variables is adequately illustrated by a negative 2 nd grade polynomic slope, decreasing faster in correspondence with lower levels of the independent variable (overloaded workers) and starting to increase at a threshold of around $35 \%$ of the distribution. This means that increasing the percentage of overloaded workers has a negative effect on productivity, at least until a certain threshold. In fact, all countries exceeding the European average (100) show a percentage of overloaded workers lower than the average (around 25-27\%).

What do these findings mean for understanding labour productivity in Southern Europe? The most relevant implication is that productivity per hour worked does not seem to increase depending only on the mere number of working hours. In other words, most productive countries are those in which there is a significant percentage of underloaded workers (more than a third of the total workforce) and a low percentage of overloaded workers (less than a quarter of the total workforce). Furthermore, workers of Mediterranean countries spend more time working than their counterparts in Liberal, Corporatist, and Social-Democratic countries. The Southern bloc countries struggle to increase their levels of productivity, given their higher level of extra hours (Table 1). 


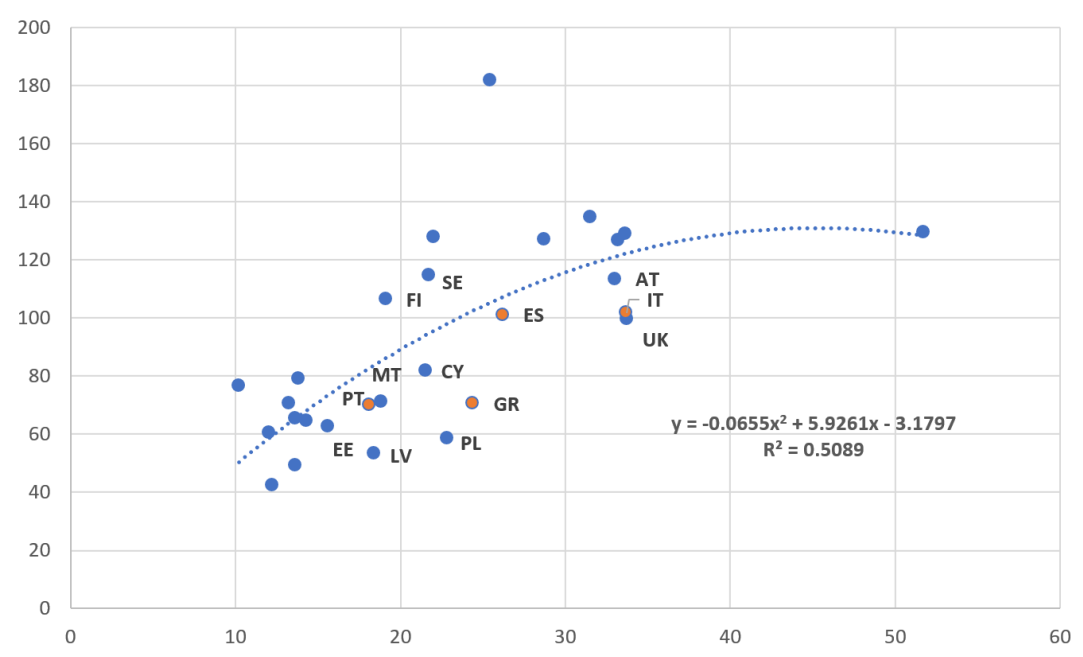

Source: EWCS

Figure 3: relation between productivity ( $y$-axis) and percent of underloaded workers (x-axis), 2015

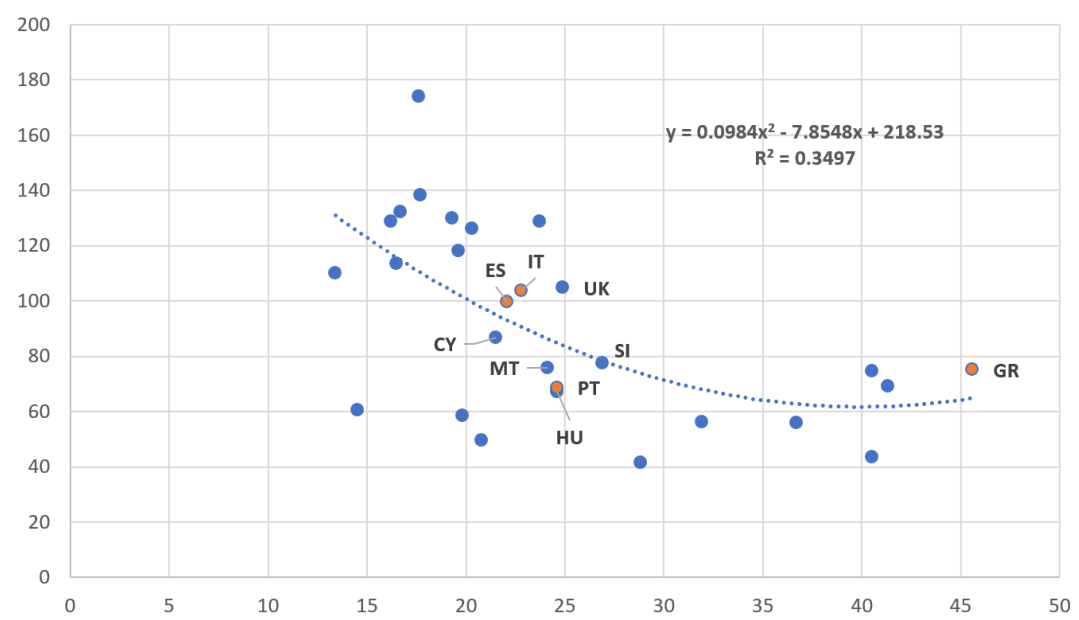

Source: EWCS

Figure 4: Relation between productivity ( $y$-axis) and overloaded workers ( $x$-axis), 2010

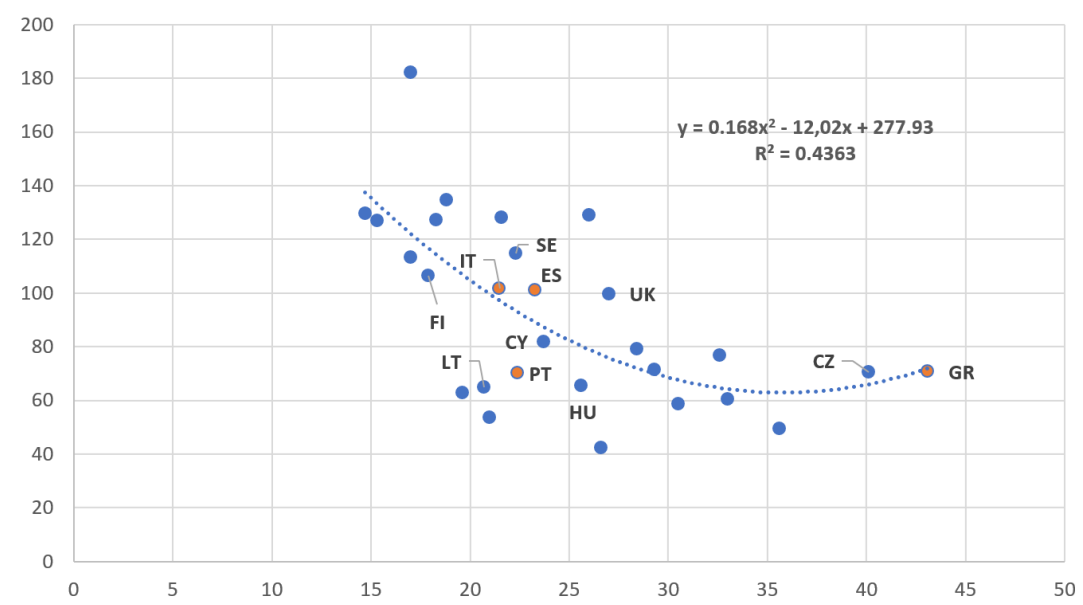

Source: EWCS

Figure 5: Relation between productivity ( $y$-axis) and overloaded workers ( $x$-axis), 2015 


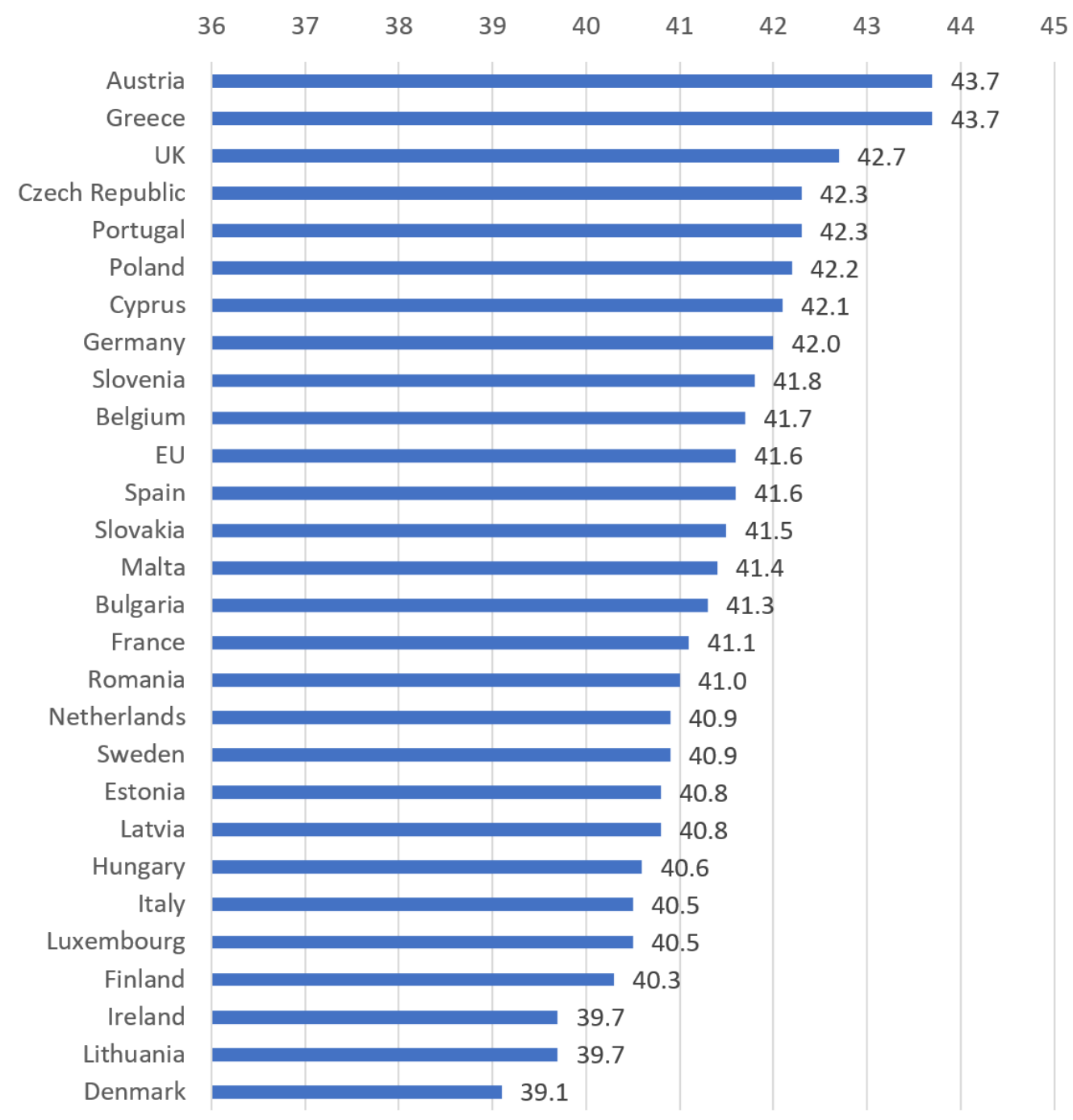

Source: EUROSTAT

Figure 6: Average of real worked hours by European countries, 2012

Another illustration of the amount of time spent working in the countries is included in the Eurostat data relating to the average of real worked hours by European countries in 2012 (Figure 6). Excluding the opposite cases of Austria (higher levels of both productivity and worked hours) and Lithuania (lower levels of both), this distribution corroborates our findings. The less productive countries of the Mediterranean area (Portugal and Greece) appear within the top five countries that dedicate most time to work. While Spain occupies a position close to the EU average, Italy exhibits medium-low levels of working hours. In turn, we find four of the most productive countries of the continent (Luxembourg, Ireland, Denmark, and Finland) among the five countries that dedicate less time to work.

Furthermore, the difference in terms of economic performance between Mediterranean countries and the other three blocs is influenced by a higher number of hours dedicated to work. In reality, it seems that a reduction of working time is a kind of 'recompense' for achieving certain levels of productivity. This virtuous relation seems particularly evident in Scandinavian countries. By contrast, we can imagine that the limited productivity of Southern countries implies an extension of their workdays. Such circumstances suggest we focus our attention on the cultural and organizational factors that inhibit productivity. Specifically, we analyse how productivity is influenced by factors such as the flexibility or the rigidness of working schedule. 


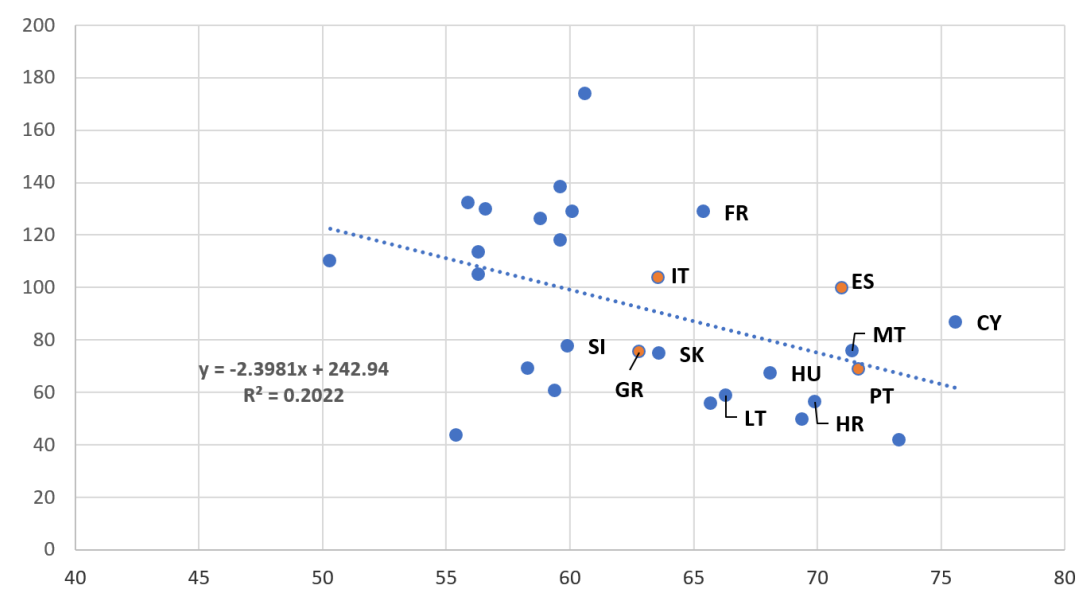

Source: EWCS

Figure 7: Relation between productivity ( $y$-axis) and rigid entry/exit schedule ( $x$-axis), 2010

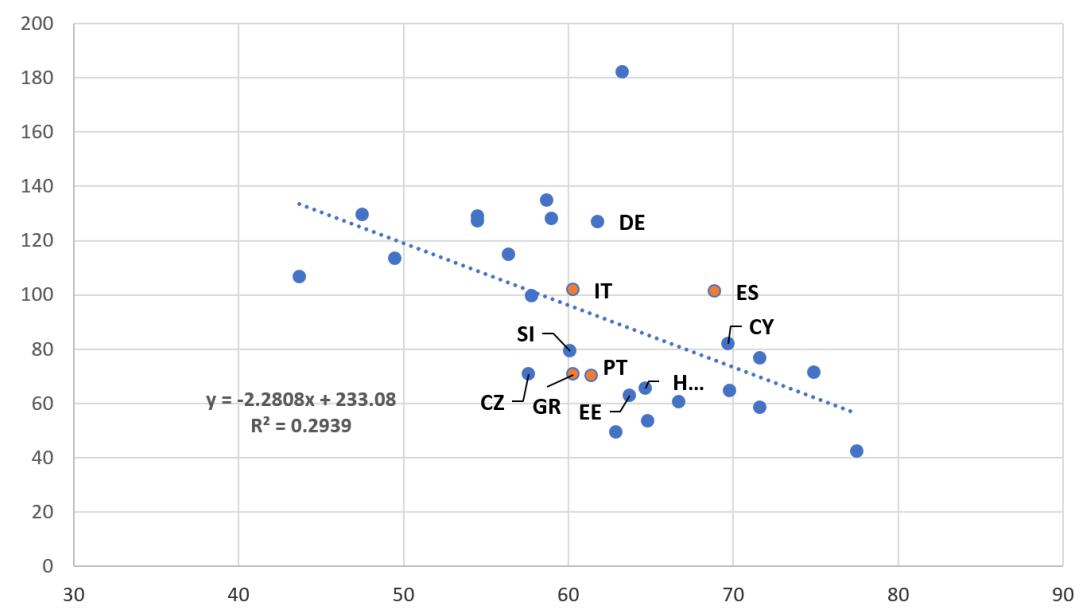

Source: EWCS

Figure 8: Relation between productivity ( $y$-axis) and rigid entry/exit schedule ( $x$-axis), 2015

\subsection{Labour Productivity and Flexible Organizational Models}

Figure 7 (2010) and Figure 8 (2015) show the relation between the aggregate levels of productivity per worked hour for each country, and the percentage of workers with a rigid entry/exit schedule. In both years, Mediterranean countries show a clear rigidity of entry and exit times at work when compared with the rest of Europe exhibiting values higher than $60 \%$ with even higher percentages for Portugal and Spain (more than $72 \%$ of their total workforces in 2010).

We observe a moderate correlation between labour productivity and the percentage of workers with a rigid entry/exit schedule. The relation between the two variables is exemplified by a negative linear slope. A coefficient of determination of 0.20 is estimated for 2010 (Figure 7) and 0.29 for 2015 (Figure 8). This means that those countries with high percentages of workers on a rigid entry-exit schedule exhibit lower levels of labour productivity. Specifically, we observe that all countries with productivity levels higher than the European average (100) exhibit a more flexible organizational model in terms of entry/exit times at work: their percentages are lower than $60 \%$, excluding France in 2010, and Luxembourg and Germany in 2015.

Figure 9 (2010) and Figure 10 (2015) show the relation between the aggregate levels 


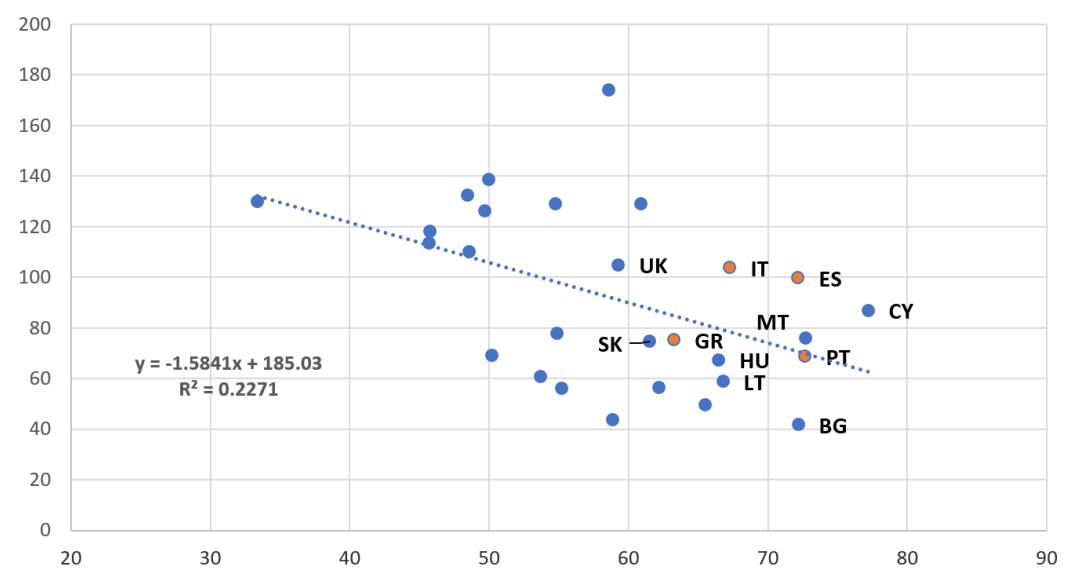

Source: EWCS

Figure 9: Relation between productivity ( $y$-axis) and rigid workday schedule ( $x$-axis), 2010

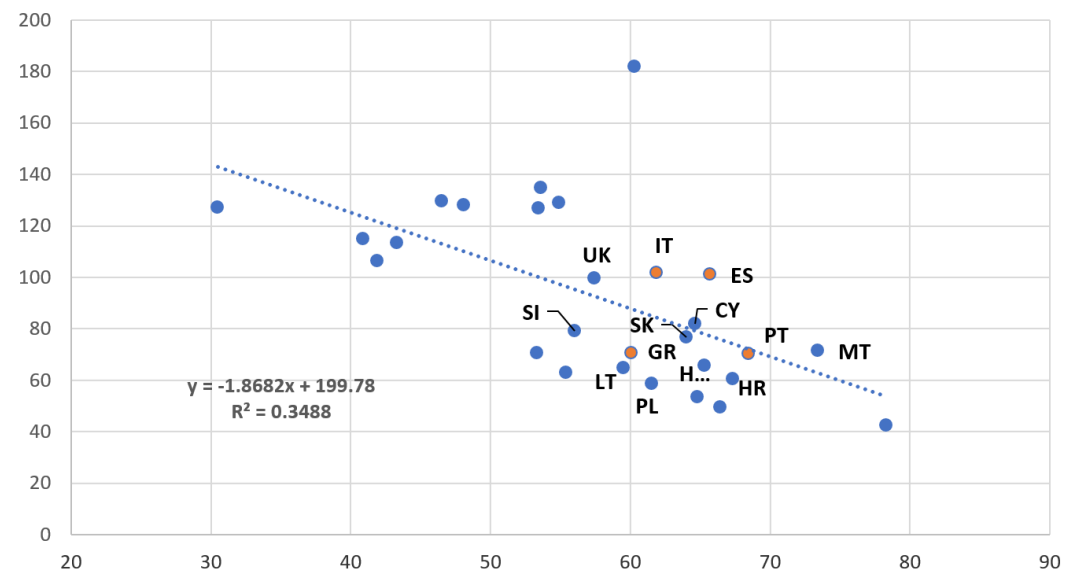

Source: EWCS

Figure 10: Relation between productivity ( $y$-axis) and rigid workday schedule ( $x$-axis), 2015

of productivity per worked hour for each country, and the percentage of workers with a rigid workday schedule. It is clear that Mediterranean countries exhibit a higher level of workers with rigid workday schedules: more than $60 \%$ in all cases and more than two thirds of the total workforce of Spain and Portugal.

We observe a moderate correlation between labour productivity and the percentage of workers with a rigid workday schedule. The relation between the two variables is exemplified by a negative linear slope. A coefficient of determination of 0.23 is estimated for 2010 (Figure 9) and 0.35 for 2015 (Figure 10). This means that countries with rigid workday schedules exhibit lower levels of labour productivity. This is the case with Mediterranean countries, exhibiting values higher than $60 \%$ both in 2010 and 2015. By contrast, we observe that all those countries with levels of productivity higher than the European average (100) exhibit more flexible organizational models in terms of daily distribution of working hours: their values are all lower than $60 \%$ in all cases.

Furthermore, our findings show that the most productive European countries exhibit organizational traits oriented toward shorter workdays and stronger flexibility of schedules. By contrast, Mediterranean countries (Italy, Spain, Portugal, Greece) have longer workdays (less in the case of Italy) and a more rigid organizational model of work time management. The divide between the Mediterranean area and the other three 'leading' varieties of capitalism is clear. 


\section{Conclusions}

We affirm the existence of relevant differences in terms of labour productivity levels between European countries according to geographical areas and national models of work time management. Following the classification schemes proposed by UNO and the varieties of capitalism literature (Hall, Soskice 2001, Amable 2003), we identified the existence of relevant differences in Europe between Western-Central countries (corporatist model), North-Western (liberal), Northern (social democratic), and the South (mixed-Mediterranean). The level of productivity per worked hour is higher in the first three blocs or more specifically, in the European productive heart. In contrast, Mediterranean countries exhibit intermediate (Spain, Italy) or lower (Greece, Portugal) levels of productivity per worked hour.

Furthermore, we observed that those countries with higher levels of productivity also exhibit lower levels of average real worked hours with the Mediterranean countries clearly positioned above the EU average (partial exception: Italy). While Mediterranean workers spend more time at work, their productivity levels are lower. This suggests the existence of a different work performance during the workday that is probably due to its longer extension and the influence of private-family issues on labour dynamics. Phenomena that are likely to have evolved from historical, cultural, and institutional issues such as the high diffusion of split-by-half workdays and the tradition of moonlighting. The resulting organizational disorder that creates 'eternal' workdays (Simmel 1998, Paugam 2007) is likely to create the impression that Mediterranean countries enter into a cycle of 'overloading' to compensate for the waste of less productive work time when confronted with the pressures of global competition and economic recession. A phenomenon that places a very high responsibility on families (and, especially, on adult women) in terms of social welfare as outlined in the Mediterranean organizational model of family care (Pfirsch 2013). In this sense, the forms of governance of the Mediterranean countries, with manifestations close to "neopatrimonialism", have reduced the potential for development of the Welfare State and, therefore, for properly developing their organization of work (Bechle 2010).

The economic performance of the most productive European countries depends on a set of cultural, organizational, and technological factors that foster labour productivity. Among these factors is the development of a flexible organizational model for work time management based on flexible entry/exit times at work and a flexible number of working hours per day. In contrast, the Mediterranean countries have evolved differently by adopting a rigid organizational model for both entry/exit times at work and the number of working hours per day, with negative consequences for productivity.

We conclude this study with a call for positive change. Looking at the recent decline of the European economy, we observe that the recent efforts of EU policies (and its powerful array of public aids) to reduce north-south imbalances have not achieved the expected results (González Rodríguez et al. 2000, De la Fuente 2005). This comparative (even if superficial) analysis of the Southern European economies contributes to a deeper appreciation of some significant factors underlying the recent episode of 'European decadence' within the global system of politico-economic relations. When evaluating future policy initiatives to rebalance the Mediterranean economies, we recommend that consideration should not only be given to the impact on productivity, but also be given to the roles to be played by national institutions in shaping the organizational models for managing work time and other labour issues. Among the various options open to national institutions, we highlight work time flexibility as an organizational strategy and value. As structural and cultural barriers such as the weight of bureaucracy and traditions are overtaken, fostering such flexibility can contribute to an increase in labour productivity in Southern European countries. Furthermore, there are worthwhile incentives to foster an institutional and organizational change in labour practices to adopt flexible work time management strategies including increased workers' satisfaction, greater work-family conciliation and reduced costs due to less work overloading. 


\section{References}

Amable B (2003) The diversity of modern capitalism. Oxford University Press, Oxford, UK. CrossRef.

Amable B (2009) Structural reforms in Europe and the (in)coherence of institutions. Oxford Review of Economic Policy 25[1]: 17-39. CrossRef.

Baldwin JR, Brown WM, Maynard JP (2005) Interprovincial differences in GDP per capita, labour productivity and work intensity: 1990-2003. No. 2005011e, Statistics Canada, Economic Analysis

Banfield E (1958) The moral basics of a backward society. The Free Press, Glencoe, IL

Basque Governement (2010) Estudio sobre las implicaciones y posibles consecuencias de un cambio horario laboral en el tejido empresarial de la CAPV, de cara a conseguir una mayor conciliación de la vida laboral and familiar. Gobierno Vasco, Departamento de Empleo and Asuntos Sociales. Vitoria

Bechle K (2010) Neopatrimonialism in Latin America: Prospects and promises of a neglected concept. Legitimacy and efficiency of political systems (GICA Research Program). Nr 153

Bratton M, Van de Walle N (1997) Democratic experiences in Africa. Regime transitions in comparative perspective. Cambridge University Press, Cambridge, UK

Brennetot A, Emsellem K, Guérin-Pace F, Garnier B (2013) Dire l'Europe à travers le monde. Cybergeo: European Journal of Geography 630. CrossRef.

Cassano F (1996) Il pensiero meridiano. Laterza, Roma-Bari

Castells M (1997) La era de la información. Alianza, Madrid

Crouch C (1998) Esiste una società europea? Stato e mercato 2: 167-202

De Jong HW (1995) European capitalism: Between freedom and social justice. Review of Industrial Organization 10[4]: 399-419. CrossRef.

De la Fuente A (2005) El impacto de la reducción de las ayudas estructurales europeas: Una primera aproximación. Presupuesto y gasto público 39: 173-190

Esping-Andersen G (1999) Los tres mundos del Estado del bienestar. Alfons el Magnánim, Valencia

EUROFOUND (2016) European working conditions survey. Acceded in 6th of July 2016, on the web site of: EUROFOUND: http://www.eurofound.europa.eu

Feld L, Otero M, Weigert B (2015) Putting Germany's 'minijobs' in their context. El País (15/10/2015). Available at https://elpais.com/elpais/2015/10/15/inenglish/1444918067_940829.html

González Rodríguez M, Martín Poveda E, Martínez García S, Santamaría Fidalgo J (2000) La desigualdad Norte-Sur en la Unión Europea. Universidad Complutense de Madrid: VII Jornadas de Economía Crítica

Guillén M (1994) Models of management: work, authority, and organization in a comparative perspective. University of Chicago Press, Chicago, IL

Halbwachs M (2002) Les causes de suicide. Coll. Le Lien Social. Paris, originally published 1930. CrossRef.

Hall PA, Soskice D (2001) Varieties of capitalism: The institutional foundations of comparative advantage. Oxford University Press, Oxford, UK. CrossRef. 
Hall RE, Jones CI (1996) The productivity of nations. No. w5812, National Bureau of Economic Research. CrossRef.

Hill J, Grzywacz S, Allen V, Blanchard V, Matz-Costa C, Shulkin S, Pitt-Catsouphes M (2008) Defining and conceptualizating work place flexibility. Community Work and Family 11: 149-163. CrossRef.

Inglehart R (1997) Modernization and Postmodernization. Princeton University Press, Princeton, NJ. CrossRef.

Jijena-Michel D, Jijena-Michel C (2015) El rol moderador de la flexibilidad del horario de trabajo en la relación del enriquecimiento trabajo familia y la satisfacción docente. Horizontes Empresariales 10[2]: 41-56

Lambert S (2000) Added benefits the link between work-life benefits and organizational citizenship behaviour. Academy of Management Journal 43: 801-815. CrossRef.

Lamo de Espinosa E (2010) Europa después de Europa. Academia Europa de las Ciencias and las Artes, Madrid

Leonardi L, Martín A, Molina O, Calenda D, Carrasquer P (2011) ¿Es exportable la flexiseguridad? Un estudio comparado de Italia y España. Cuadernos de Relaciones Laborales 29[2]: 417-443. CrossRef.

Lewis S (2003) Flexible working arrangements: Implementations, outcomes and management. In: Cooper C, Roberts I (eds), Annual Review of Industrial Psychology, Volume 18. Wiley-Blackwell, New York, NY, 1-28. CrossRef.

López-Pintor R, Wert J (1982) La otra España: Insolidaridad e intolerancia en la tradición político-cultural española. Revista Española de Investigaciones Sociológicas 19: 292-307

Lusa A, et al (2007) Gestión de los horarios de trabajo en presencia de cláusulas de flexibilidad pasiva. Universia Business Review 14[2]: 10-25

Maya M (2016) El ocaso del chavismo. Venezuela (2005-2015). Alfa, Montevideo, Uruguay

Maynard JP (2007) The comparative level of GDP per capita in Canada and the United States: A decomposition into labour productivity and work intensity differences. The Canadian Productivity Review, 15-206

Meardi G (2012) Mediterranean capitalism'under EU pressure: Labour market reforms in Spain and Italy, 2010-2012. Warsaw Forum of Economic Sociology 3[1]: 51-81

MGI - McKinsey Global Institute (2010) Más allá de la austeridad: Un camino hacia el crecimiento económico y la renovación en Europa. McKinsey Global Institute. London, UK. Available at http://www.mckinsey.com/insights/mgi/research/productivity_competitiveness

Migdal J (1998) Strong societies and weak states: State-society relations and state capabilities in the Third World. Princeton University Press, Princeton NJ

Miguélez F, Prieto C (2009) Transformaciones del empleo, flexibilidad y relaciones laborales en Europa. Política and Sociedad 46[2]: 275-287

Moerland PW (1995) Corporate ownership and control structures: An international comparison. Review of industrial organization 110[4]: 443-464. CrossRef.

Paugam S (2007) Las formas elementales de la pobreza. Alianza, Madrid

Perrons D (2005) Gender mainstreaming and gender equality in the new economy. An analysis of contradiction. International Journal of Politics 7[4]: 389-411

Pfirsch T (2013) Une géographie de la famille en Europe du Sud. Cybergeo: European Journal of Geography. 533. CrossRef. 
Pizzorno A (1966) Amoral familism and historical marginality. International Review of Community Development 15: 55-66

Regini M (1995) La varietà italiana di capitalismo. Istituzioni sociali e struttura produttiva negli anni Ottanta. Stato e mercato 43[2]: 3-21

Segura J (2006) La productividad en la economía española. Fundación Ramón Areces, Madrid

Simmel G (1998) Les pauvres. Coll. Cuadrige, Paris. Originally published 1907

Van de Walle N (2005) Economic reform. Patterns of constraints. In: Gyimah-Boahdi E (ed), Democratic reform in Africa. The quality of progress. Lynne Rienner, Boulder, CO

Villena A (2017) ¿Cómo se gobierna España? La estructura de las élites gubernamentales en 2004 y 2016. Comares, Granada, Spain

() () (C) 2018 by the authors. Licensee: REGION - The Journal of ERSA, European

Regional Science Association, Louvain-la-Neuve, Belgium. This article is distri-

buted under the terms and conditions of the Creative Commons Attribution, Non-Commercial (CC BY NC) license (http://creativecommons.org/licenses/by-nc/4.0/). 